\section{Unveiling the face of Selene}

\section{S.R. Taylor}

The Geologic History of the Moon. US Geological Survey Professional Paper 1348. By Don E. Wilhelms with sections by John F. McCauley and Newell J. Trask. US Government Printing Office:1987. Pp.302 + 25 colour plates. $\$ 33$.

Don Wilhelms has put together the definitive study of the stratigraphy and geological history of the Moon. The chief glory of the book is in the carefully chosen and well-reproduced pictures, which are complemented by Wilhelms's sage commentary. Perceptive sections on Orientale by John McCauley and on crater morphology by Newell Trask add to the book's value. The text draws deeply on the accumulated wisdom of the USGS Astrogeology Branch in Flagstaff, Arizona. Wilhelms pays generous tributes both to his co-workers and to the pioneering work of Gene Shoemaker, based on his definitive study of Meteor Crater, Arizona, itself the subject of long debate among geologists obsessed with internal, rather than external processes.

Among the various insights to be gained from the book are that it is hazardous to take the Earth as an analogy for the Moon, confirming the view that much terrestrial geochemistry and petrology is unique to this planet; that simple rather than complex explanations of lunar features are usually correct; and that lunar craters are all effectively the result of impact (even the curious case of crater Kopff), despite the desperate attempts of proponents of explosive volcanism to turn them into volcanic calderas. It is salutary to read of all these past controversies and of the problems of interpretation of photographs in the absence of 'ground truth'.

Some controversies remain unresolved. The nature of the Apennine Bench Formation, whether impact-generated, analogous to the Montes Rook Formation of the Orientale Basin, or composed of KREEP basalt, beloved of petrologists, must await further missions. The lunar cataclysm, a long-lived but erroneous view of lunar cratering history, is dismissed in one succinct paragraph (pp. 190-191). Wilhelms also comments mildly on the petrological versus the stratigraphical approach; both disciplines need each other. Thus "names derived from terrestrial igneous petrology have been applied, inappropriately, to rocks melted and emplaced by impacts" (p.139). In this context, Wilhelms's careful delineation of the distinction between impact basins and the later voluminous lavas which fill them

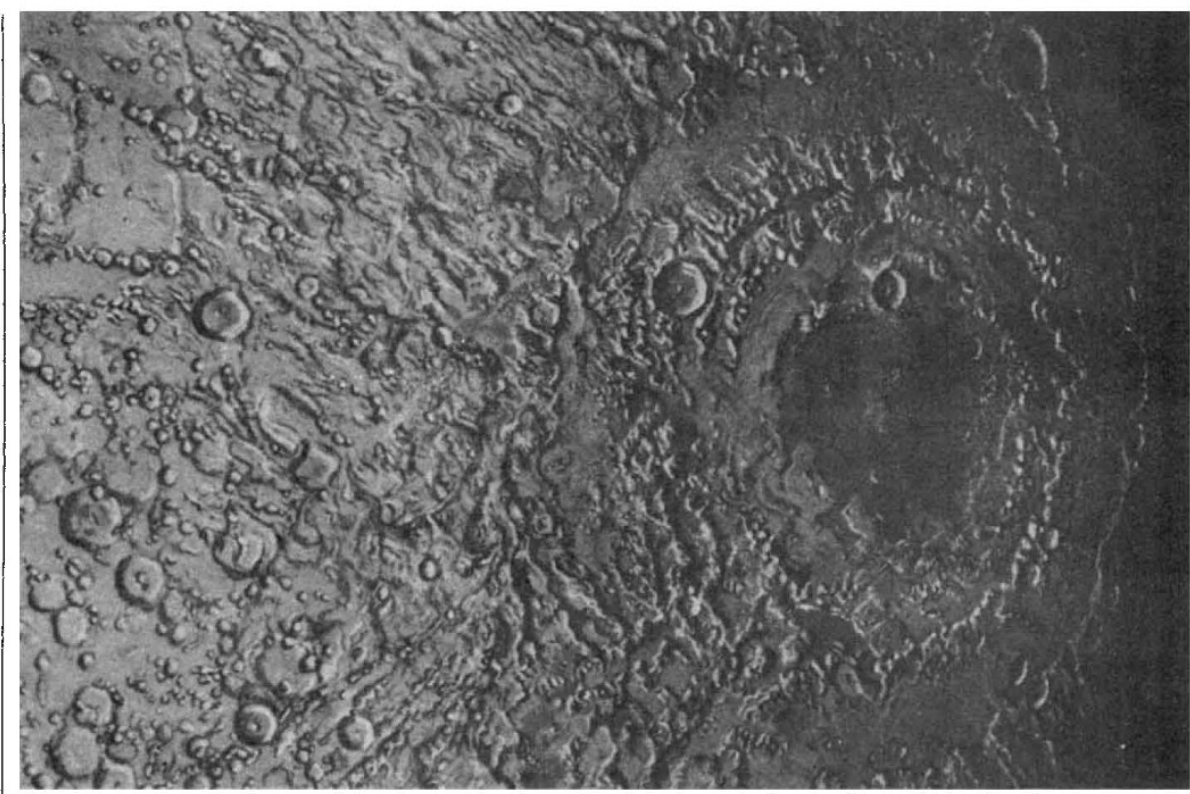

The young one - Orientale basin and its deposits, from a painting by Donald E. Davis.

to form the maria should help to remove another lingering misconception.

Readers will be enlightened on many topics: the problems of using lunar craters to date surfaces (common sense abounds in the treatment of this difficult technique); the origin of the sinuous rilles; the misconceptions about lunar structure and tectonics which led to the 'lunar grid', and the final realization that the crustal structure is dominated by the effects of the giant ringed basins, which are themselves the result of asteroidal or planetesimal impact.

It is worth contemplating these structures (of which the type example is the youngest, the $900-\mathrm{km}$ diameter Orientale Basin dating from about $3.8 \times 10^{9} \mathrm{yr}$ ago). The formation of multi-ring basins is ascribed to fluidization, rather than slumping into a deep initial cavity. Their effects outside the basin itself are remarkable: "a continuous deposit extends outward for an average distance of $450 \mathrm{~km}$ or one basin radius from Montes Cordillera [the outer ring of the Orientale basin].

In some sections, dense clusters of secondaries (craters) extend $900 \mathrm{~km}$ (two basin radii) from the Cordillera. Secondaries also extend beyond $1850 \mathrm{~km}$ in at least one ray-like string" (p.66). This enormous structure, with all its complex stratigraphy, formed in minutes.

Evidence of such processes must give pause to those seeking rocks older than $3.8 \times 10^{9} \mathrm{yr}$ on the Earth. Current estimates indicate that at least 200 such basins, with diameters greater than 1,000 $\mathrm{km}$, formed on Earth in the interval 4.4-3.8 $\times 10^{9} \mathrm{yr}$ ago, thus explaining the absence of identifiable terrestrial rock units. The impact melts and breccias from this epoch would have been easy meat for terrestrial eroding agents; in contrast, the lunar examples are still preserved on the bone-dry Moon.
Perhaps the most notable aspect of the book is the emphasis on the importance of the Procellarum Basin (originally perceived as the Gargantuan Basin by Peter Cadogan), a stupendous structure 3,200 $\mathrm{km}$ in diameter, within which nestle most of the later near-side basins and mare basalt flows. This basin may be responsible for the thinness of the near-side lunar crust, the prevalence of near-side mare basalt, the widespread flooding of Oceanus Procellarum and much more.

Wilhelms wisely refrains from discussing the origin of the Moon, a question which has been resolved only since the completion of the book. But his endeavours to place lunar stratigraphy on a sound footing have helped to place constraints on the problem.

Full justice to the photographs and drawings is done by the generous format $(28 \times 37 \mathrm{~cm})$. But this is a coffee-table book with a difference, for there are ten pages of references which constitute a very useful lunar bibliography. The cover is enhanced by a sequence of drawings, well worth close study, by Don Davis, who also provides other illustrations through the book. A final delight at the end of the text is the sequence of 24 superb colour plates, summarizing ringed basins, maria, and lunar structure and stratigraphy.

There is so much accumulated wisdom in this book that a reviewer can only hope to provoke readers to delve into it for themselves. It should serve as a model for similar studies of the other planets and satellites. As Wilhelms comments (p.139), "the lunar pre-Nectarian System provides our closest look at the early Solar System", and that is probably our ultimate scientific justification for going to the Moon.

S.R. Taylor is at the Research School of Earth Sciences, Australian National University, GPO Box 4, Canberra 2601, Australia. 